\title{
The utility of Heart type Fatty Acid Binding Protein in Acute Myocardial Infarction Patients
}

\author{
Subrat Chandra ${ }^{1}$, Manish Raj Kulshrestha ${ }^{2}$, Apurva Raj ${ }^{3 *}$, Bhuwan Chandra Tiwari ${ }^{4}$ \\ ${ }^{1}$ Department of Pathology, Dr. Ram Manohar Lohia Institute of Medical Sciences, Lucknow Uttar Pradesh India \\ ${ }^{2}$ Department of Biochemistry, Dr. Ram Manohar Lohia Institute of Medical Sciences, Lucknow Uttar Pradesh India \\ ${ }^{3}$ Department of Pathology, Superspeciality Cancer Institute, Lucknow Uttar Pradesh India \\ ${ }^{4}$ Department of Cardiology, Dr. Ram Manohar Lohia Institute of Medical Sciences, Lucknow Uttar Pradesh India
}

\begin{abstract}
DOI: $10.36348 /$ sjpm.2020.v05i02.013 $\quad$ | Received: 14.02 .2020 | Accepted: 21.02 .2020 | Published: 29.02 .2020
*Corresponding author: Dr. Apurva Raj
\end{abstract}

Abstract

Introduction: Early diagnosis and therapeutic intervention can improve the outcome of acute myocardial infarction (AMI). However, there are no satisfactory cardiac biomarkers for the diagnosis of AMI within 6 hours of onset of symptoms. Among the novel biomarkers of AMI, we tested the diagnostic accuracy of Heart type Fatty Acid Binding Protein (HFABP) in prospectively recruited patients with independently adjudicated outcomes. Methods: Prospective observational study was conducted at the Department of Pathology and Department of Cardiology, Dr Ram Manohar Lohia Institute of Medical Sciences Lucknow. After taking informed consent, 80 cases of chest pain suggestive of coronary origin (within 6 hours) were included. Results: Group a included 55 patients while Group B included 25 patients. In our study on Receiver operator curve (ROC) analysis, the AUC (Area under curve) was 0.846 (95\% C.I. 0.743 to 0.948 ; $\mathrm{p}$ value <0.001) for HFABP. The optimum cut-off value for HFABP to diagnose AMI was $6.38 \mathrm{ng} / \mathrm{ml}$ with a Sensitivity, Specificity, PPV (Positive Predictive Value) and NPV of 86.4\%, 84.5\%, 67.9\% and 94.2\% respectively. Conclusion: The optimum cut-off value for HFABP to diagnose AMI was found to be $6.38 \mathrm{ng} / \mathrm{ml}$ were in concordance with similar studies. A high sensitivity and NPV is essential for the early 'rule out' of AMI patients. Since more than $70 \%$ of patients who present with acute chest pain to an emergency department do not have AMI, HFABP can be used as rule out tool to prevent unnecessary admissions of patients suspected for AMI considering its high sensitivity and NPV. Though, it was not a reliable marker for AMI diagnosis because of low specificity and positive predictive value. Further larger studies are needed to understand whether HFABP can add incremental value in rule-in AMI.

Keywords: Acute myocardial infarction, Heart type fatty acid binding protein, Rule out Tool.

Copyright @ 2020: This is an open-access article distributed under the terms of the Creative Commons Attribution license which permits unrestricted use, distribution, and reproduction in any medium for non-commercial use (NonCommercial, or CC-BY-NC) provided the original author and sources are credited.

\section{INTRODUCTION}

Myocardial infarction is defined by the clinical history, electrocardiogram, and an increase or decrease in cardiac troponin concentration (as evidence of myocardial necrosis) [1]. Assessing chest pain patients presenting to the emergency area (EA) is still a clinical challenge, as acute myocardial infarction (AMI) diagnosis is not adjudicated in the majority of patients. Acute Myocardial Infarction (AMI) accounts for 5-15\% of all the causes of chest pain in USA. In countries like India, considerably higher number of patients present with chest pain as the chief complaint to the emergency department. The incidence of MI in India is 64.37/1000 people [2]. The overall prevalence of coronary heart disease (CHD) in Lucknow district was found to be $7.1 \%$ with $8.8 \%$ in urban areas and $3.8 \%$ in rural areas [3]. Epidemiological studies showed 29.8 million coronary heart disease patients in India and 1.27 million acute coronary events resulting in 20,000 coronary bypass surgeries and 1,113,359 coronary angioplasties per year. As per World Health Organisation (WHO) data, the Coronary Artery Disease (CAD) prevalence continues to rise in India with rapid 'epidemiological transition'. It has already surpassed communicable diseases as the major cause of mortality in India. It has been projected that between 1990 and 2020, there will be $117 \%$ and $105 \%$ rise in mortality from CAD in men and women respectively in India [4]. In a typical population of patients undergoing evaluation for acute chest pain in emergency department, about $15 \%$ to $25 \%$ have AMI. By accurately ruling out chest pain of cardiac origin, $40 \%$ of patients presenting with acute chest pain could be spared from the risks and costs of unnecessary hospital admission and more invasive cardiac testing [2]. A missed diagnosis of acute coronary syndrome (ACS) may lead to further ischemic 
events in a potentially preventable death or disability. Therefore, patients with symptoms suggestive of ACS often undergo a lengthy assessment in the emergency department (ED) or as hospital in patients. These patients account for approximately $10 \%$ of Emergency Department presentations and $25 \%$ of hospital admissions, yet up to $85 \%$ do not have a final diagnosis of ACS. International guidelines for the investigation of ACS recommend serial measurement of cardiac troponin (cTn) at the onset of symptoms which is more cumbersome process for identifying patients with low short-term risk of adverse cardiac events and to support their earlier discharge.

Among all, Heart type fatty acid binding protein (HFABP) has been largely investigated. It is a small $(15 \mathrm{kDa})$ soluble protein, present in cardiomyocytes cytoplasm at high concentrations [5]. It is rapidly released into plasma after the onset of myocardial injury, with a peak at approximately 6-8 hours [6].

\section{METHODS}

Prospective observational study was conducted at the Department of Pathology and Department of Cardiology, Dr Ram Manohar Lohia Institute of Medical Sciences Lucknow, from February 2016 to September 2018 after institutional ethical clearance (IEC number 31/16). The study included 80 cases of Chest pain suggestive of coronary origin on the basis discretion of emergency department cardiologist assessment and/or ECG findings.

The patients admitted to cardiology department at RMLIMS fulfilling inclusion criteria will be taken in study. $2 \mathrm{ml}$ blood sample in EDTA vial was taken. HFABP was estimated after centrifugation at $3000 \mathrm{rpm}$ for 10 minutes, the serum was separated. Following serum creatinine was estimated by modified Jaffe's assay kinetic assay on Beckmann coulter AU480. HFABP was estimated by Enzyme Linked Immune Sorbent Assay (ELISA), based on biotin double antibody sandwich technology respectively (Biovendor research and diagnostic products).

Groups were formed and compared: The patients was further subgrouped based on the basis of onset of chest pain-

Group A: Time of first sampling is within 3 hours of onset of chest pain

Group B: Time of first sampling is $>3$ hours of onset of chest pain

The performance of HFABP was analysed with their serum levels in sample taken at the time of presentation in terms of sensitivity, specificity, positive predictive value and negative predictive value. All these performances were analysed and compared with SPPSS version 21 .

Patients presenting with acute chest pain of less than six-hour duration suspected of coronary origin were enrolled. These patients were also randomly classified according time of chest pain onset into two groups ( $<3$ hours and $>3$ hours). Full history taking including patients' symptoms and past medical history such as diabetes mellitus (DM), hypertension (HTN) and previous ischemic event; and general clinical examination, ECG and laboratory investigations were documented at admission using a pre-defined protocol.

The standard diagnosis was made after critical review of all the clinical pictures and relevant information by a senior cardiologist. AMI was defined according to the European Society of Cardiology/American College of Cardiology Committee Criteria. AMI was defined as detection of initial or 0-3 h hsTnI above 99 percentile upper reference limit (URL) together with evidence of myocardial ischemia with at least one of the following:

(i). Symptoms of ischemia

(ii). ECG changes indicative of new ischemia (new ST$\mathrm{T}$ changes or new left bundle branch block [LBBB]

(iii).Development of pathological Q waves in the ECG (iv). Imaging evidence of new loss of viable myocardium or new regional wall motion abnormality.

Diagnostic outcomes were first categorized into the following groups:

(i).ST-elevation myocardial infarction (STEMI)

(ii). Non-ST-elevation myocardial infarction (NSTEMI)

(iii). Unstable angina (UA)

(iv). Non-cardiac chest pain (NCCP).

The first two groups were later integrated into AMI group, and the last two into non-myocardial infarction (non-AMI) group.

The diagnosis of chest pain cases as myocardial infarction will be taken as finalized by cardiologists.

\section{INCLUSION CRITERIA}

1. Age $>18$ Years

2. Consent taken.

3. Chest pain suggestive of coronary origin on the basis discretion of emergency physician/ cardiologist assessment and/or ECG findings with with at least one hsTnI level above the upper 99th percentile (Upper Reference Limit or URL).

\# Chest pain suggestive of coronary origin is defined, in accordance with ACC/AHA guidelines, as chest or left arm pain as the chief symptom. ECG changes suggestive of ischemia are defined as pathologic Q waves of more than $40 \mathrm{msec}$, ST- 
segment elevation or depression of more than $1 \mathrm{~mm}$ or abnormal $\mathrm{T}$ wave morphology.

\section{EXCLUSION CRITERIA}

1. Chronic renal failure (eGFR below $60 \mathrm{ml} / \mathrm{min}$ )

2. Acute history of muscle injury/ trauma

3. Patients not willing to provide blood sample

4. Patients with previous history of AMI

Two venous blood samples $(2 \mathrm{ml})$ were withdrawn and blood serum was separated from the clot and aliquoted under complete aseptic condition. The serum obtained was kept frozen at -40 degree centigrade till the analysis of serum creatinine and HFABP.

The H-FABP was determined by enzyme linked immunosorbant assay (ELISA, Biovendor research and diagnostic products). The assay system uses a double antibody sandwich enzyme linked immunosorbent one step process assay (ELISA) to determine the level of HFABP in samples.

\section{RESULTS}

In present study eighty consecutive patients with complain of acute chest pain of less than six hours suggestive of cardiac origin were evaluated in the department of cardiology, RMLIMS, Lucknow. Majority of patients belonged to the age group $>61$ years $(40 \%)$ and the mean age of presentation was 58.5 Yrs and the main bulk of the study population between 40 to 70 years of age. Incidence of AMI was more common in male, patients with past medical history of hypertension, smoking and diabetes mellitus. In cases diagnosed as AMI, 50\% of the patients found to have ST elevation. $17.5 \%$ of patients were diagnosed as unstable angina and $55 \%$ cases were diagnosed as having non-cardiac chest pain. In sub group analysis group, A included 55 patients while sub group B included 25 patients. In our study on Receiver operator curve (ROC) analysis, the AUC (Area under curve) was 0.846 (95\% C.I. 0.743 to 0.948 ; p value <0.001) for HFABP. The optimum cut-off value for HFABP to diagnose AMI was $6.38 \mathrm{ng} / \mathrm{ml}$ with a Sensitivity, Specificity, PPV and NPV of $86.4 \%, 84.5 \%, 67.9 \%$ and $94.2 \%$ respectively.

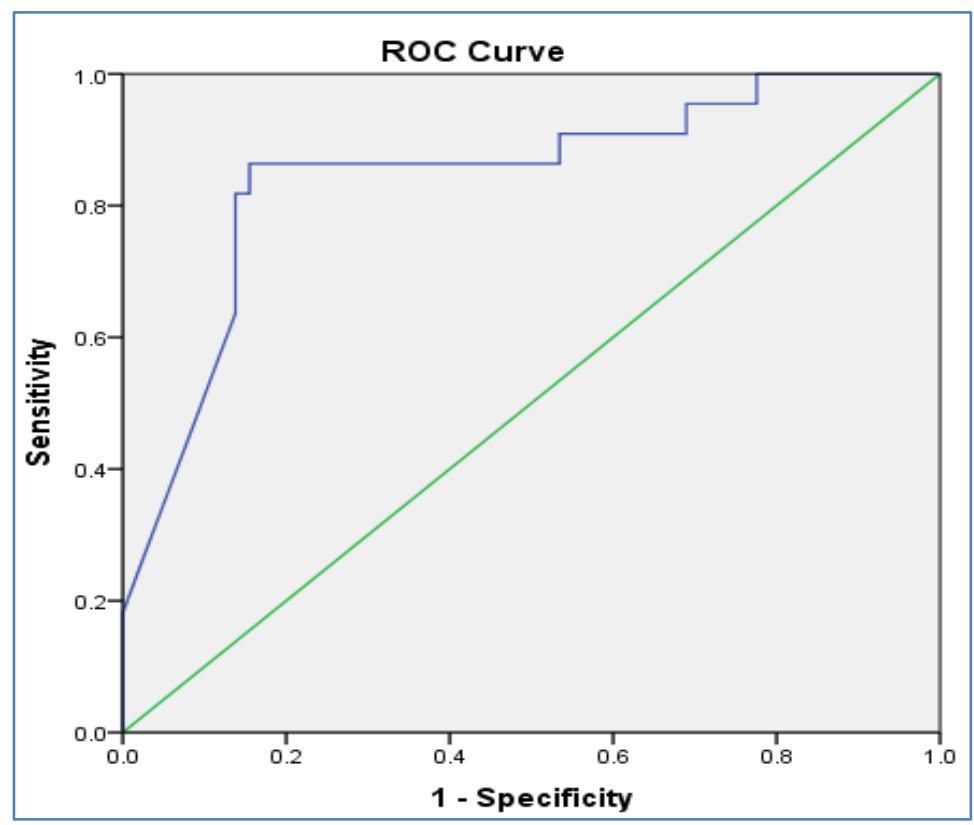

Diagram-1: The ROC analysis of HFABP at the time of admission

Table-1: Analysis of AMI patients using HFABP

\begin{tabular}{|c|c|c|c|c|}
\hline TIME GROUP & \multirow[t]{2}{*}{$\begin{array}{c}\text { HFABP } \\
\text { ELEVATION }\end{array}$} & \multicolumn{2}{|c|}{$\begin{array}{l}\text { MYOCARDIAL } \\
\text { INFARCTION }\end{array}$} & \multirow[t]{2}{*}{ TOTAL } \\
\hline \multirow{4}{*}{$\begin{array}{c}\text { GROUP A } \\
\text { Presentation }<3 \mathrm{hr}\end{array}$} & & Yes & No & \\
\hline & Yes & 9 & 6 & 15 \\
\hline & No & 3 & 37 & 40 \\
\hline & & 12 & 43 & 55 \\
\hline \multirow{3}{*}{$\begin{array}{l}\quad \text { GROUP B } \\
\text { Presentation >3 } \\
\text { hr }\end{array}$} & Yes & 10 & 3 & 13 \\
\hline & No & 0 & 12 & 12 \\
\hline & & 10 & 15 & 25 \\
\hline
\end{tabular}


HFABP in group A showed Sensitivity, Specificity, PPV and NPV of $75 \%, 86 \%, 60 \%$ and
92.5\% while in group B showed Sensitivity, Specificity, PPV and NPV of $100 \%, 80 \%, 76.9 \%$ and $100 \%$.

Table-2: The performance of HFABP (HFABP > $6.38 \mathrm{ng} / \mathrm{mL}$ were considered for AMI) at the time of admission

\begin{tabular}{|c|c|c|c|}
\hline & $\begin{array}{c}<3 \text { hours presentation } \\
(\mathbf{n = 5 5})\end{array}$ & $\begin{array}{c}>3 \text { hours presentation } \\
(\mathbf{n = 2 5})\end{array}$ & Overall \\
\hline Sensitivity (\%) & 75 & 100 & 86.4 \\
\hline Specificity (\%) & 86 & 80 & 84.5 \\
\hline PPV (\%) & 60 & 76.9 & 67.9 \\
\hline NPV (\%) & 92.5 & 100 & 94.2 \\
\hline
\end{tabular}

In 9 subjects $(11.25 \%)$ out of 80 acute chest pain patients HFABP was falsely elevated. The most common cause was being unstable angina in our study.

Table-3: High HFABP levels (>6.38 ng/ml) in different subgroups based on final diagnosis

\begin{tabular}{|c|c|c|c|}
\hline Elevated HFABP & Final diagnosis & n & HFABP $>\mathbf{6 . 3 8} \mathbf{~ n g} / \mathbf{m l}$ \\
\hline $\begin{array}{c}\text { True Positive } \\
(\mathrm{n}=19)\end{array}$ & STEMI & 11 & $11(100 \%)$ \\
\cline { 2 - 4 } & NSTEMI & 11 & $08(72.7 \%)$ \\
\hline $\begin{array}{c}\text { False Positive } \\
(\mathrm{n}=09)\end{array}$ & Unstable Angina & 14 & $05(35.7 \%)$ \\
\cline { 2 - 4 } & Non cardiac chest pain & 44 & $04(9.1 \%)$ \\
\hline & Total & 80 & $28(35 \%)$ \\
\hline
\end{tabular}

\section{DISCUSSION}

In our study eighty consecutive patients with complain of acute chest pain of less than six hours and suggestive of cardiac origin were evaluated in the department of cardiology, RMLIMS, Lucknow. Incidence of AMI was more common in male, patients with past medical history of hypertension, smoking and diabetes mellitus. The reason being the abovementioned factors are the known risk factors for coronary heart disease. In our study, we did also find that mean age of presentation was 58 years with $40 \%$ patients were above 61 years of age. Majority (86.3\%) were males with diabetes mellitus and hypertension significantly more in AMI cases than non AMI patients ( $\mathrm{p}$ value 0.027 and 0.031 respectively).

In cases diagnosed as AMI, $50 \%$ of the patients found to have ST elevation. $17.5 \%$ of patients were diagnosed as unstable angina and $55 \%$ cases were diagnosed as having noncardiac chest pain and out of which $13.7 \%$ cases showed $\mathrm{T}$ wave inversion. The diagnostic value of the admission ECG is limited ifi) the presence of conduction disorders including left bundle branch block (LBBB); ii) If $\mathrm{Q}$ waves and ST-T changes are already present e.g. old infarcts. iii) ST-T wave changes of marked left ventricular hypertrophy; iv) In posterior infarct or right ventricular infarct. $30 \%$ of patients may have no diagnostic changes on their admission ECG.

In our study on Receiver operator curve (ROC) analysis, the AUC (Area under curve) was 0.846 (95\% C.I. 0.743 to 0.948 ; $\mathrm{p}$ value $<0.001$ ).

Table-4

\begin{tabular}{|l|l|}
\hline Study & $\begin{array}{l}\text { Area under Curve (95\% Confidence } \\
\text { Interval) AUC (95\% C.I.) }\end{array}$ \\
\hline Kellens S et al. [7] & $0.830(0.770-0.890)$ \\
\hline Ruff TC et al. [8] & $0.780(0.720-0.840)$ \\
\hline Eggers KM et al. [9] & $0.800(0.760-0.840)$ \\
\hline Reddy LL et al. [10] & $0.728(0.622-0.817)$ \\
\hline Present Study & $0.846(0.743$ to 0.948$)$ \\
\hline
\end{tabular}

The optimum cut-off value for HFABP to diagnose AMI was $6.38 \mathrm{ng} / \mathrm{ml}$ with sensitivity, specificity, PPV and NPV of $86.4 \%, 84.5 \%, 67.9 \%$ and
$94.2 \%$ respectively. The cut off value in our study is in concordance with similar studies. 
Table-5: illustrated that the prespecified cut-off value for HFABP varied between studies, a cut-off between5 to $7 \mathrm{ng} / \mathrm{ml}$ was used, four studies used the same assay and the same cut-off point (>6.38 $\mathrm{ng} / \mathrm{mL})$ for abnormality [11]

\begin{tabular}{|c|c|c|c|c|c|}
\hline Author & Study type & $\begin{array}{c}\text { Study } \\
\text { population }\end{array}$ & $\begin{array}{c}\text { Index test } \\
\text { threshold } \\
(\mathrm{ng} / \mathrm{ml})\end{array}$ & $\begin{array}{l}\text { Index test } \\
\text { assay }\end{array}$ & $\begin{array}{l}\text { Time from } \\
\text { symptoms }\end{array}$ \\
\hline Vupputuri2015 & India, singlecentre & 54 & 6.4 & $\begin{array}{c}\text { abbott } \\
\text { Architect }\end{array}$ & Up to 6 hours \\
\hline Pyati 2015 & India, Single centre & 80 & 6.3 & Roche C-311 & $<3$ Hours \\
\hline Gerede 2015 & Turkey, Single Centre & 48 & 7.0 & CardioDetect & $<3$ Hours \\
\hline Willemsen 2015 & Netherland, Single Centre & 88 & 5.3 & Fab Pulous BV & $<3$ Hours \\
\hline Gami 2015 & India, Single Centre & 88 & 5.1 & ELISA & Up to 6 hours \\
\hline Kellens S 2015 & Belgium, Single Centre & 203 & 5.3 & Fab Pulous BV & Up to 6 hours \\
\hline Dupuy AM 2015 & France, Single Centre & 181 & 5.8 & Randox-Cobas & Up to 6 hours \\
\hline Kitamura 2013 & Japan, Single Centre & 63 & 6.2 & ELISA & $<3$ Hours \\
\hline Kagawa Y 2013 & Japan, Single Centre & 114 & 5.8 & ELISA & Up to 6 hours \\
\hline Garcia 2011 & Spain, Single Centre & 165 & 6.2 & ELISA & $<3$ Hours \\
\hline McMahon 2012 & Ireland, Single Centre & 1128 & 5.2 & Randox-Cobas & $<3$ Hours \\
\hline Xu Q 2010 & China, Single Centre & 87 & 7.0 & CardioDetect & $<3$ Hours \\
\hline Liao J 2009 & China, Single Centre & 74 & 7.0 & CardioDetect & $<3$ Hours \\
\hline Mad P 2007 & Austria, Single Centre & 107 & 7.0 & CardioDetect & $<3$ Hours \\
\hline Seino Y 2004 & Japan, Single Centre & 35 & 6.2 & ELISA & $<3$ Hours \\
\hline Seino Y 2003 & Japan, Single Centre & 371 & 6.2 & ELISA & $<3$ Hours \\
\hline Body R 2011 & UK, Single Centre & 705 & 6.8 & ELISA & $<3$ Hours \\
\hline Reiter M 2013 & Switzerland, Single Centre & 1074 & 4.2 & QuickSensh & $<6$ Hours \\
\hline Ruff CT 2013 & US, Single Centre & 343 & 5.0 & Randox & Up to 6 hours \\
\hline Aldous 2012 & New Zealand, Single Centre & 384 & 6.0 & Hycult & $<3$ Hours \\
\hline Eggers 2012 & Sweden, Multi Centre & 360 & 5.8 & Randox & Up to 6 hours \\
\hline Collinson 2014 & UK, Multi Centre & 850 & 6.0 & ELISA & $<3$ Hours \\
\hline Reddy LL et al. & Chennai, India & 88 & 6.32 & Randox & $<6$ hours \\
\hline Present Study & Lucknow, Single Center & 80 & 6.3 & ELISA & $<6$ Hours \\
\hline
\end{tabular}
other studies.

Sensitivity and specificity of H-FABP was significantly high in present study which is consistent with various

Table-6: The performance of HFABP in different studies

\begin{tabular}{|l|c|c|c|c|}
\hline \multicolumn{1}{|c|}{ Study } & Sensitivity $\mathbf{( \% )}$ & Specificity (\%) & PPV (\%) & NPV (\%) \\
\hline Ruff TC et al. [8] & 63 & 79 & 51 & 85 \\
\hline Van Hise CB et al. [12] & 99.1 & 43.4 & 12.9 & 100 \\
\hline Fissha MZ et al. [13] & 75 & 83.7 & 30 & 93.3 \\
\hline Kellens S et al. $[7]$ & 54 & 84 & 85 & 52 \\
\hline Elma bouh I et al. $[14]$ & 81.8 & 88.2 & 81.8 & 88.2 \\
\hline Vupputuri et al. $[15]$ & 100 & 85.7 & 88.2 & 100 \\
\hline Present study & 86.4 & 84.5 & 67.9 & 94.2 \\
\hline
\end{tabular}

\section{CONCLUSION}

A high sensitivity and NPV is essential for the early 'rule out' of AMI patients. Since more than 70\% of patients who present with acute chest pain to an emergency department do not have AMI, H-FABP can be used as rule out tool to prevent unnecessary admissions of patients suspected for AMI considering its high sensitivity and NPV. On the other side it can be stated that HFABP is clearly not a reliable marker for AMI diagnosis because of low specificity and PPV. Relatively larger studies and more interventional trials are needed to understand whether HFABP can add incremental value in rule-in AMI.

\section{REFERENCES}

1. Thygesen, K., Alpert, J.S., Jaffe, A.S.(2012). Third universal definition of myocardial infarction. Circulation; 126: 2020-35.
2. Jena, B.N., Kadithi, A. (2009). Study of Risk Factors Affecting the Survival Rate of Emergency Victims with "Chest Pain" as Chief Complaint. Indian J Community Med, 34(4):293-97.

3. Joshi. (2013). Int J Biol Med Res, 4(1): 29662972.

4. World Health Organization. (1998). World Health Organization; Geneva, Switzerland: World Health Statistics Annual.

5. Alhadi, H.A., Fox, K.A. (2004). Do we need additional markers of myocyte necrosis: the potential value of heart fattyacid-binding protein QJM, 97(4): 187-98.

6. Ishii, J., Wang, J.H., Naruse, H. (1997). Serum concentrations of myoglobin vs human heart-type cytoplasmic fatty acid-binding protein in early detection of acute myocardial infarction. Clin Chem, 43(8): 1372-8. 
7. Kellens, S., Verbrugge, F. H., Vanmechelen, M., Grieten, L., Van Lierde, J., Dens, J., ... \& Vandervoort, P. (2016). Point-of-care heart-type fatty acid binding protein versus high-sensitivity troponin $\mathrm{T}$ testing in emergency patients at high risk for acute coronary syndrome. European Heart Journal: Acute Cardiovascular Care, 5(2), 177184.

8. Ruff, C. T., Bonaca, M. P., Kosowsky, J. M., Conrad, M. J., Murphy, S. A., Jarolim, P., ... \& Morrow, D. A. (2013). Evaluation of the diagnostic performance of heart-type fatty acid binding protein in the BWH-TIMI ED chest pain study. Journal of thrombosis and thrombolysis, 36(4), 361-367.

9. Eggers, K. M., Venge, P., \& Lindahl, B. (2012). High-sensitive cardiac troponin $\mathrm{T}$ outperforms novel diagnostic biomarkers in patients with acute chest pain. Clinica Chimica Acta,413(13-14), 1135-1140.

10. Reddy, L. L., Shah, S. A., Dherai, A. J., Ponde, C. K., \& Ashavaid, T. F. (2016). Troponin T and Heart Type Fatty Acid Binding Protein (h-Fabp) as Biomarkers in Patients Presenting with Chest Pain. Indian Journal of Clinical Biochemistry, 31(1), 87-92.

11. Xu, L. Q., Yang, Y. M., Tong, H., \& Xu, C. F. (2018). Early diagnostic performance of heart- type fatty acid binding protein in suspected acute myocardial infarction: evidence from a metaanalysis of contemporary studies. Heart, Lung and Circulation, 27(4), 503-512.

12. Van Hise, C. B., Greenslade, J. H., Parsonage, W., Than, M., Young, J., \& Cullen, L. (2018). External validation of heart-type fatty acid binding protein, high-sensitivity cardiac troponin, and electrocardiography as rule-out for acute myocardial infarction. Clinical biochemistry, 52, 161-163.

13. Fissha, M. Z., Maddox, W. R., Mohamad, A., Looney, S. W., \& Janiak, B. D. (2011). Rapid Assessment and Triaging of Acute Chest Pain Patients Using Huma n Fatty Acid Binding Protein (the RASTA study): Are we ready for prime time. J Clinic Experiment Cardiol, 2(119), 2.

14. Elmadbouh, I., Mahfouz, R., Bayomy, N., Faried, W., \& Ghanayem, N. (2012). The value of human heart-type fatty acid binding protein in diagnosis of patients with acute chest pain. The Egyptian Heart Journal, 64(4), 179-184. Vupputuri, A., Sekhar, S., Krishnan, S., Venugopal, K., \& Natarajan, K. U. (2015). Heart-type fatty acidbinding protein (H-FABP) as an early diagnostic biomarker in patients with acute chest pain. Indian heart journal, 67(6), 538-542. 